\title{
Erratum to "Arterial Spin Labeling (ASL) fMRI: Advantages, Theoretical Constrains and Experimental Challenges in Neurosciences"
}

\author{
Ajna Borogovac and Iris Asllani \\ Department of Radiology, Columbia University, New York, NY 10032, USA \\ Correspondence should be addressed to Iris Asllani, ia2026@columbia.edu \\ Received 31 May 2012; Accepted 5 June 2012 \\ Copyright (C) 2012 A. Borogovac and I. Asllani. This is an open access article distributed under the Creative Commons Attribution \\ License, which permits unrestricted use, distribution, and reproduction in any medium, provided the original work is properly \\ cited.
}

The old title in the original paper was "Arterial Spin Labeling (ASL) fMRI: Advantages, Theoretical Constrains and Experimental Challenges in Neurosciences" and it will be changed to "Arterial Spin Labeling (ASL) fMRI: Advantages, Theoretical Constraints, and Experimental Challenges in Neurosciences." 

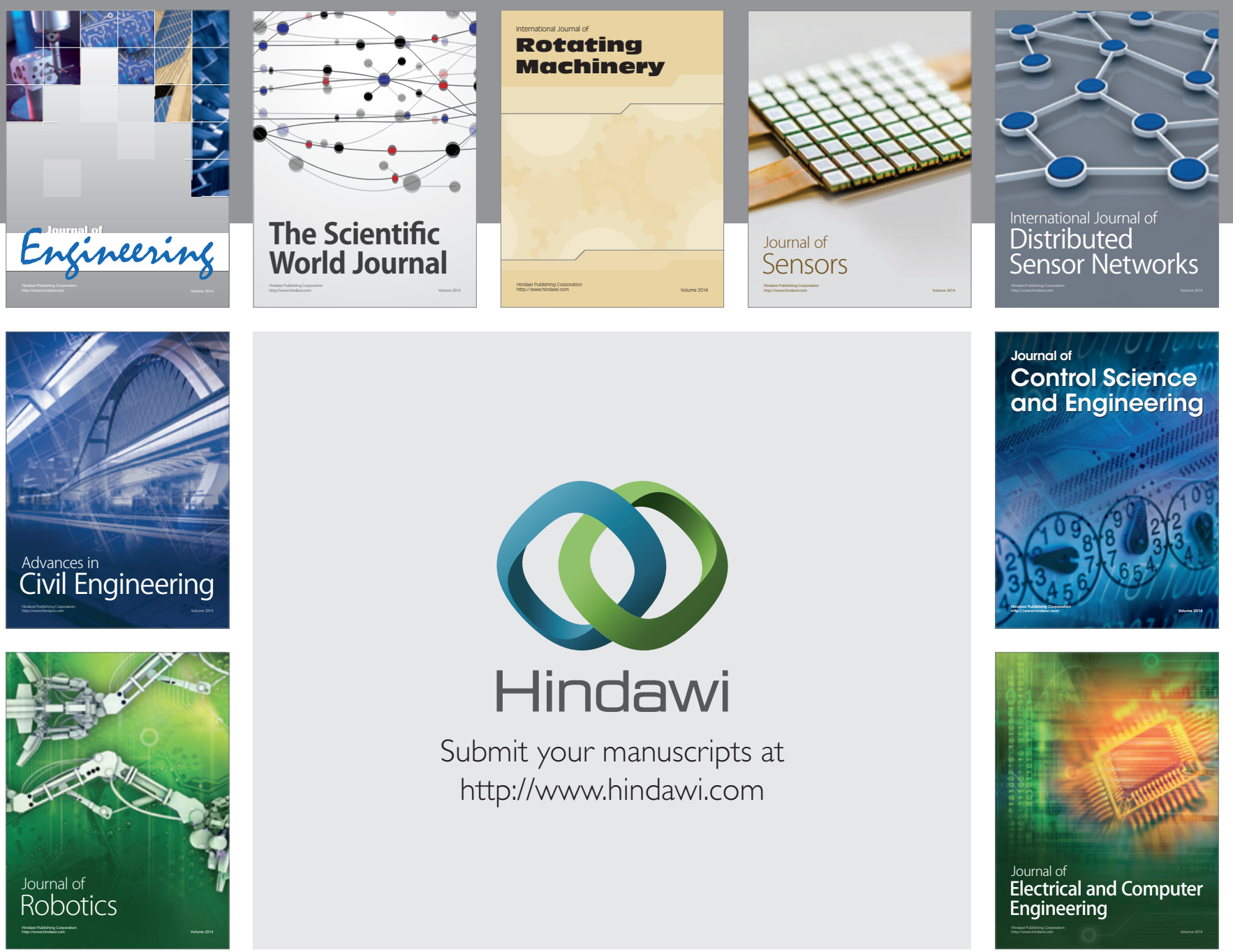

Submit your manuscripts at

http://www.hindawi.com
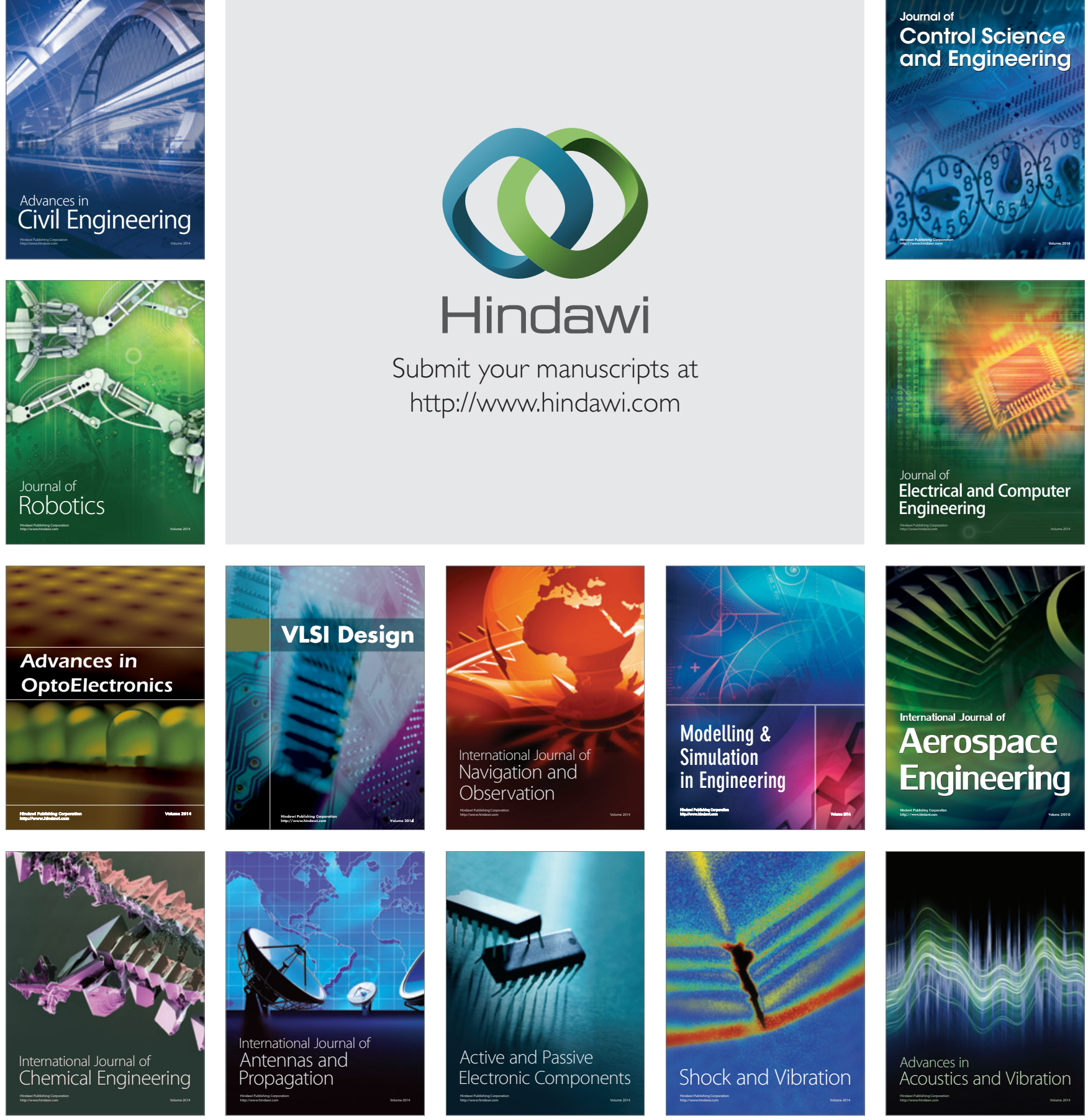